\author{
Н.А. Потапова ${ }^{*}$ \\ Статистические методы \\ в изучении политических репрессий \\ в Западной Сибири в 1937-1938 гг. \\ (по материалам Комиссии НКВД \\ и Прокурора СССР)
}

\author{
DOI: 10.31518/2618-9100-2019-4-7 \\ УДК 94(571.53):316.477-055.2
}

Выходные данные для цитирования:

Потапова Н.A. Статистические методы в изучении масштабов политических репрессий в Западной Сибири в 1937-1938 гг. (по материалам Комиссии НКВД и Прокурора СССР) // Исторический курьер. 2019. № 4 (6). Статья 7. URL: http://istkurier.ru/data/2019/ISTKURIER-2019-4-07.pdf
N.N. Potapova

\section{Statistical methods for studying} the political repression in Western Siberia in 1937-1938 (based on materials from the NKVD Commission and the Prosecutor of the USSR)

\author{
DOI: $10.31518 / 2618-9100-2019-4-7$
}

How to cite:

Potapova N.A. Statistical methods for studying the scale of political repression in Western Siberia in 19371938 (based on materials from the NKVD Commission and the Prosecutor of the USSR) // Historical Courier, 2019, \#4 (6). Article 7. [Available online:] http://istkurier.ru/data/2019/ISTKURIER-2019-407.pdf

Abstract. The article is devoted to the experience of using statistical methods in the study of Soviet political terror. The author notes that the use of statistical methods in historical research has become possible thanks to the involvement of mass sources. Databases created on the basis of investigative cases of the repressed, and statistical methods allow us to study various waves of persecution in the USSR, including the period of the Great Terror. Based on the decisions of the Commission of the NKVD and the Prosecutor of the USSR, the author of the work compiled a database containing protocol digital information on the extent of the repression in the regions of the USSR. Using statistical methods in analyzing the database, the extent of "national" operations in Western Siberia was determined. Of the eleven «national» punitive lines in the region, ten were drawn. The Novosibirsk region has become a leader not only in the number of people arrested, but also in the cruelty of sentences. Here, 13,308 people went through «national» operations, including 12,821 people were sentenced to death $(96 \%)$. The number of people repressed by "linear" punitive actions in Altai was almost three times lower (4353 people). The percentage of those who received capital punishment was $78.7 \%$. The repressions were relatively sluggish in the Omsk region (1,637 repressed), and sentences in the first category did not exceed $45 \%$. The analysis showed that the proportion of convicts of "national" punitive action in the West Siberian region amounted to $8 \%$ of the total number of repressed for this mass operation in the country.

Keywords: statistical methods; databases, the Great Terror; the Commission of the NKVD and the Prosecutor of the USSR; Western Siberia.

The article has been received by the editor on 10.08.2019.

Full text of the article in Russian and references in English are available below.

Аннотация. Статья посвящена опыту применения статистических методов в изучении советского политического террора. Автор отмечает, что применение методов статистики в исторических исследованиях стало возможным благодаря привлечению массовых источников. Базы данных, созданные на основании следственных дел репрессированных, и

\footnotetext{
* Потапова Наталья Анатольевна, стажер-исследователь Института истории СО РАН (Новосибирск, Россия), e-mail: skna17talya@mail.ru

Potapova Natalia Anatolievna, trainee-researcher, Institute of History of the Siberian Branch of the Russian Academy of Sciences (Novosibirsk, Russia), e-mail: skna17talya@mail.ru
} 
статистические методы позволяют изучать различные волны преследований в СССР, в том числе и период Большого террора. На основании решений Комиссии НКВД и Прокурора СССР автором работы была составлена база данных, содержащая протокольные цифровые сведения о масштабах репрессий в регионах СССР. Применяя статистические методы при анализе базы данных были определены масштабы «национальных» операций в Западной Сибири. Из одиннадцати «национальных» карательных линий в регионе было проведено десять. Новосибирская область стала лидером не только по количеству арестованных, но и по жестокости выносимых приговоров. Здесь по «национальным» операциям прошло 13308 чел., в том числе к расстрелу приговорили 12821 чел. (96 \%). Почти в три раза меньше (4353 чел.) численность репрессированных по «линейным» карательным акциям на Алтае. Процент получивших высшую меру наказания составил 78,7 \%. Сравнительно вяло прошли репрессии в Омской области (1637 репрессированных), а приговоры по первой категории не превышали 45 \%. Анализ показал, что доля осужденных по «национальным» карательным акциям в западносибирском регионе составила $8 \%$ от общего числа репрессированных по этой массовой операции в стране.

Ключевые слова: статистические методы; базы данных, Большой террор; Комиссия НКВД и Прокурора СССР; Западная Сибирь.

Статистические методы в исторических исследованиях используются не только при работе с так называемыми статистическими источниками, представляющие собой в исходном виде цифровой материал, но и с массовыми источниками, к которым относят массив однотипных по структуре и составу содержащейся в них информации документов. Подобного рода сведения легко поддаются формализации и приведению к количественному значению с дальнейшей статистической обработкой. Методы статистики предназначены в том числе и для работы с неколичественной информацией, ведь они всегда имеют дело с совокупностями, группами, то есть массовым материалом, а не с отдельными случаями, объектами, индивидуумами. Соответственно, при описании совокупности данных, можно прибегнуть к статистическому подсчету, а, следовательно, и к использованию методов статистики. Таким образом, математизация исторической информации - это разноплановое и масштабное явление, которое не ограничивается на привлечении и обработки данных, содержащих непосредственно количественные сведения в узком значении.

Широкое привлечение массовых источников в исторические работы приходится на конец 1950-х-начало 1960-х гг. Параллельно происходит активное обращение историков к статистическим методам, эффективная обработка которых стала возможной только благодаря методам статистики. Еще одна причина, вызывавшая интерес к статистическим методам, заключалась в стремлении историков повысить информативную отдачу источника. Статистические методы позволяли вывести исторические исследования на качественно новый уровень, получить более точные данные о прошлом, проверить уже имеющиеся теоретические знания предыдущих поколений историков.

$\mathrm{C}$ «архивной революции», с получения историками частичного доступа к ранее закрытым чекистским документам, статистические методы стали использоваться для изучении советского политического террора. Особенно активно к таким методам стали прибегать при работе с следственными делами репрессированных. Нередко одним из этапов изучения чисток в СССР становится создание базы данных по биографическому массиву сведений. Базы данных и статистические методы применяются в исследовании различных волн репрессий, примером служат работы А.А. Ракова ${ }^{1}$, С.Л. Разинкова ${ }^{2}$, Н.В. Звеняцкой ${ }^{3}$ и др.

\footnotetext{
${ }^{1}$ Раков A.A. Социально-экономические аспекты «раскулачивания» крестьян Южного Урала (1930-1934 гг.). M.,2012.

${ }^{2}$ Разинков С.Л. Социальный портрет советских немцев-трудармейцев, мобилизованных в лагеря НКВД на
} 
До настоящего времени Большой террор привлекает внимание историков из-за тех серьезных общественно-политических, культурных, экономических и демографических последствий, которые он породил. В последние годы отечественная и зарубежная историография далеко продвинулись в изучении наиболее массовой карательной акции 19371938 гг, проводимой на основании приказа НКВД СССР № 00447 от 30 июля 1937 г. ${ }^{4}$ Успехов удалось достичь, в том числе, и благодаря привлечению нового корпуса источников, которые ранее были засекречены. К таковым относятся следственные дела репрессированных, а также протоколы внесудебных инстанций («кулацких» троек). Еще одна массовая операция Большого террора, «национальная» карательная акция, изучена крайне фрагментарно. До настоящего времени в историографии отсутствует обобщающий труд по истории проведения этой карательной акции. Основная причина заключается в труднодоступности источниковой базы. В России до настоящего времени документы НКВД в основном хранятся в ведомственных архивах ФСБ (бывших КГБ), за исключением некоторых регионов, в их числе Алтайский край, где материалы внесудебных инстанций и прекращенные архивноследственные дела были переданы на государственное хранение. К настоящему времени исследователи могут работать только с рассекреченными чекистскими материалами 1930-х гг., однако список таких документов, как правило, отсутствует. Несмотря на ограниченный доступ к решениям внесудебных инстанций ряд исследователей получили возможность ознакомиться с некоторыми из них. Объем информации, содержащейся в подобного рода документах, требовал ее строгой систематизации. Для этого на основании следственных дел репрессированных и протоколов внесудебных органов историки прибегли к созданию баз данных. На основании таких баз историки (И.Г. Джуха, Г.Д. Жданова, М. Юнге, Р. Биннер) исследовали не только социальный портрет репрессированных, но и масштаб террора в регионе.

Весь объем существующих протоколов внесудебных инстанций до сих пор не обработан, основная причина заключается в том, что, например, решения «кулацких» троек хранятся в регионах функционирования этого органа. Кроме того, они находятся в ведомственных архивах, которые, зачастую, не допускают историков к работе с документами 1937-1938 гг. Частичный доступ к делопроизводственной документации НКВД получил исследователь И.Г. Джуха, который один из первых обработал решения Комиссии НКВД и Прокурора СССР по «греческой» операции. Благодаря этому он ввел в научный оборот численность репрессированных, обвиненных в «греческом» шпионаже, в СССР и в отдельных регионах страны5. На региональном уровне исследованием «кулацкой» операции и серии «национальных» карательных акций на основе анализа протоколов внесудебных инстанций занималась Г.Д. Жданова. Важной заслугой автора является то, что она одна из первых показала историю проведения двух массовых операций Большого террора («кулацкой» и серии «национальных» операций) на Алтае, используя протоколы тройки и Комиссии НКВД и Прокурора $\mathrm{CCCP}^{6}$. Коллективу историков под руководством немецких историков М. Юнге

территории Свердловской области в 1941-1946 гг:: опыт создания и применения электронной базы данных: автореф. дисс. ... канд. ист. наук. Екатеринбург, 2001.

3 Звеняцкая Н.В. Социальный портрет «врага народа» в 1920-1930-е гг. (по материалам Нижнетагильского округа) // Тагильский край в панораме веков. Материалы научно-практической конференции г. Нижний Тагил, 12-13 мая 1999 г. Екатеринбург, 1999. С. 98-104.

${ }^{4}$ Юнге М., Биннер Р. Как Террор стал «Большим». Секретный приказ № 00447 и технология его исполнения. М., 2003; Юнге М., Бордюгов Г., Биннер Р. Вертикаль большого террора. История операции по приказу НКВД № 00447. М., 2008; Через трупы врага на благо народа. «Кулацкая операция» в Украинской ССР 1937-1941 гг.: в 2 т. / сост.: М. Юнге, С.А. Кокин, Р. Биннер, А.О. Довбня, Б. Бонвеч, И.Е. Смирнова, Г.А. Бордюгов; под. общ. ред. О.А. Довбни, Л.С. Макаровой. М., 2010; Большевистский порядок в Грузии: в 2 т. / сост.: М. Юнге, Б. Бонвеч, О. Тушурашвили. М., 2015.

5 Джуха И.Г. Греческая операция. История репрессий против греков в СССР. СПб., 2006.

${ }^{6}$ Жанова Г.Д. Политические репрессии на Алтае 1919-1938 гг.: историко-статистическое исследование. Барнаул, 2015. 
и Р. Биннера удалось получить доступ к делопроизводственной документации НКВД Грузинской ССР. Впервые в историографии Большого террора историки рассмотрели вместе три массовые операции НКВД: операция по приказу № 00447 («кулацкая» операция), операция по «национальным линиям» и социальная чистка («милицейская» тройка) ${ }^{7}$. Н.А. Потаповой удалось получить доступ ко всем протоколам Комиссии НКВД и Прокурора СССР и обработать их. На основании этих документов исследователь обозначила масштабы террора и особенности его проведения в Алтайском ${ }^{8}$ и Красноярском ${ }^{9}$ краях, Казахской ${ }^{10}$, Украинской $^{11}$, Армянской, Грузинской и Азербайджанской ${ }^{12}$ республиках.

Интерес к протоколам внесудебных инстанций вызван тем, что именно они в период Большого террора обеспечивали массовость репрессий. Приговоры по «кулацкой» операции выносили тройки, реанимированные приказом № 00447 от 30 июля 1937 г. Внесудебные полномочия органы ВЧК получили еще в начале 1918 г. ${ }^{13}$ Для вынесения приговоров была создана особая внесудебная инстанция - тройка. После завершения Гражданской войны тройки продолжали свою деятельность, но масштабы их работы сократились. Для проведения «кулацкой» операции в 68 регионах страны образовывался этот внесудебный орган, в состав которого входили начальник НКВД (УНКВД), прокурор (республики, края, области) и секретарь партийной организации (республик, краев и областей). Параллельно с «кулацкими» тройками работала Комиссия НКВД и Прокурора СССР («двойка»), которая до сентября 1938 г. занималась рассмотрением дел по «национальным» операциям. «Двойка» была создана по приказу № 00485 от 11 августа 1937 г., в ее состав входили нарком внутренних дел Н.И. Ежов и прокурор СССР А.Я. Вышинский, иногда их заместители. Комиссия НКВД и Прокурора СССР выносила приговоры на основании пришедших из регионов справок на арестованных («альбомная» справка). Утвержденные «двойкой» решения вносились в протокол, который мог содержать сведения от одного-двух до тысячи человек. Подписанный документ отправлялся в регионы для приведения приговора в действие.

Протоколы Комиссии НКВД и Прокурора СССР включают в себя списки лиц, приговоренных к расстрелу, лагерю или другим видам наказания, а также отражают передачу дел по подсудности, на доследование. Для «национальных» операций заводились протоколы на основании данных одного «альбома» или сразу нескольких. В протоколах обязательно указывался номер оперативного приказа, в рамках которого осуждались арестованные. Нумерация протоколов велась в рамках операции по каждому оперативному приказу и в валовом порядке по мере поступления материалов из республик, краев и областей. Всего Комиссия НКВД и Прокурора СССР подписала 3417 протокола, из них по «польской» операции - 1251, «немецкой» - 447, «харбинской» - 590, «греческой» - 133, «иранской» - 50, «румынской» - 185, «эстонской» - 70, «финской» - 78, «латышской» - 305, «афганской» - 8, «смешанной» - 300 ${ }^{14}$. Все протоколы однотипны. В них указан номер протокола, дата,

\footnotetext{
${ }^{7}$ Большевистский порядок в Грузии: в 2 т. / сост.: М. Юнге, Б. Бонвеч, О. Тушурашвили. М., 2015.

${ }^{8}$ Потапова Н.А. «Харбинская» операция НКВД СССР1937-1938 гг. в Алтайском крае // Вестник Томского государственного университета. История. 2017. № 47. С. 75-80.

${ }^{9}$ Потапова Н.А. «Харбинская» операция НКВД СССР (сентябрь 1937 - ноябрь 1938 гг.) в Красноярском крае: общее и особенное в организации и проведении репрессивной акции [Электронный ресурс] // Исторический курьер. 2019. № 1. URL: http://istkurier.ru/data/2019/ISTKURIER-2019-1-06.pdf (дата обращения: 02.07.2019 г.).

${ }^{10}$ Жанбосинова А.C., Потапова Н.A. Масштабы и региональные особенности «национальных» операций в Казахской CCP [Электронный ресурс] // Исторический курьер. 2019. № 1. URL: http://istkurier.ru/data/ 2019/ISTKURIER-2019-1-09.pdf (дата обращения: 02.07.2019 г.).

${ }^{11}$ Потапова Н.А. «Харбинская» операция в Украине (сентябрь 1937 - ноябрь 1938 гг.) // Актуальные проблемы исторических исследований: взгляд молодых ученых : сборник материалов Всероссийской молодежной научной школы-конференции. Новосибирск, 14-16 сентября 2017 г. Новосибирск, 2017. С. 209-220.

${ }^{12}$ Потапова Н.А. «Национальные» операции НКВД СССР в советских республиках Южного Кавказа (сентябрь 1937-ноябрь 1938 гг.) // Вестник архивов Армении. 2018. № 126. С. 293-305.

${ }^{13}$ Из истории Всероссийской Чрезвычайной комиссии 1917-1921 гг. Сборник документов. М., 1958. С. 95-96.

${ }^{14}$ УФСБ по Омской области. Ф. 6 (Протоколы Комиссии НКВД и Прокурора СССР).
} 
должности и фамилии лиц, присутствовавших на заседании (нарком внутренних дел СССР и прокурор СССР или их заместители), далее идут вводная часть («слушали: материалы на обвиняемых, представленные ... (территориальный орган НКВД) в порядке приказа № (номер соответствующего приказа, в рамках которого проводилась репрессия), постановляющая часть (список репрессированных и утвержденные приговоры), в конце протокола - должности и фамилии присутствовавших на заседании, а также печать НКВД СССР и подписи наркома внутренних дел СССР Н. И. Ежова и прокурора СССР А.Я. Вышинского, или их заместителей. Постановляющая часть протокола разбита на две колонки. Содержание левой колонки менялось на протяжении всего периода проведения «национальных» операций. До середины октября 1937 г. в протоколах указывали только фамилию, имя и отчество осужденного, после этой даты к анкетным сведениям репрессированного добавили год и место рождения, с середины мая 1938 г. - подданство. Справа, напротив фамилии каждого обвиняемого, указывали репрессивное решение (прописными буквами), в том числе: расстрелять, заключить в исправтрудлагерь на ... лет, дело доследовать, предать суду Военной Коллегии Верхсуда СССР, дело передать в суд и т. д. Содержание правой колонки тоже изменялось. До конца октября 1937 г. вместо «исправтрудлагерь» указывалось «заключить в концлагерь».

Данные протоколов дают богатый материал для изучения «национальных» операций. В них указан не только орган, представивший список репрессированных (территориальные органы НКВД или ДТО ГУГБ НКВД), но и республики, края и области, приславшие списки, что позволяет детально воспроизвести региональную статистику чисток по карательным акциям. Кроме того, на их основании можно проследить динамику утверждения приговоров, работу Комиссии НКВД и Прокурора СССР, а также сосчитать количество приговоров о расстреле, лагерном заключении (от 3 до 10 лет), ссылке, высылке из страны, сколько дел было передано на доследование, на рассмотрение Военной коллегии Верховного суда СССР, в военные трибуналы, суды, под гласный надзор.

На основании 3417 протоколов Комиссии НКВД и Прокурора СССР по «национальным» операциям нами была создана электронная база данных с использованием программы MicrosoftExcel, входящей в стандартный набор прикладных программ пакета MicrosoftOffice. Всего в базе 20 полей, 18 из которых охватывают данные, содержащиеся в каждом протоколе, в их числе номер протокола, дата утверждения, территориальный орган НКВД или ДТО, представивший «альбом», республика, город, всего включенных в список протокола, из них приговоренных к расстрелу, к 10, 8, 5, 3 годам исправительно-трудовых лагерей, к ссылке или высылке, передано на доследование, на рассмотрение Военной коллегии Верховного суда СССР, в военные трибуналы, суды, под гласный надзор, всего отложено, освобождены. Еще 2 поля включают количественную информацию, не отраженную в протоколе, но подсчитанную с помощью программы. Поле «всего осуждено» показывает сумму статистических данных приговоренных Комиссией НКВД и Прокурора СССР к различным мерам наказания, поле «всего отложено» иллюстрирует количество дел, переданных на доследование или на рассмотрение судебным инстанциям. База дает широкие возможности для иллюстрации общесоюзного масштаба террора, региональной статистики проведения «национальных» операций, численности репрессированных территориальными органами НКВД (УНКВД) и ДТО ГУГБ НКВД, динамику вынесения приговоров. При задании определенного критерия поиска (или нескольких критериев) программа покажет результаты выборки.

Для определения масштабов репрессий по «национальным» операциям в Западной Сибири рассмотрим отдельно размах террора в Новосибирской, Омской областях и Алтайском крае. «Польская» операция стала самой массовой в западносибирском регионе. По протоколам Комиссии НКВД и Прокурора СССР прошло 8339 чел., что составило 7,9 \% от общего числа осужденных по приказу № 00485 в стране. Наибольшего размаха и жестокости репрессии достигли в Новосибирской области, здесь «двойка» осудила 6067 чел., 
включая 5890 чел., или 97 \%, - к высшей мере наказания, 148 чел (2 \%). - к исправительнотрудовым лагерям (ИТЛ). На Алтае по «польской» карательной акции прошло 1266 чел., т.е. почти в пять раз меньше, чем в соседней Новосибирской области. Утвержденные Комиссией НКВД и Прокурора СССР были мягче. Высшая мера наказания применялась к 1005 чел. (79\%), в лагеря попали 207 чел. (16\%). В Омской области было осуждено 1066 чел., при этом только 439 чел. (43,6 \%) приговорили к смертной казни, 515 чел., или 51 \% - к лагерному заключению.

По «немецкой» карательной акции в Западной Сибири прошло 3916 чел., или 12,5% от общего числа репрессированных по приказу № 00439. Особенно массово чистки в отношении «немецких» шпионов прошли в Алтайском крае, где было осуждено 2175 чел., в том числе к расстрелу - 1760 чел. $(89,9$ \%) и лагерному заключению - 371 чел (17\%). УНКВД по Новосибирской области в Москву предоставила дела в отношении 1698 чел., обвиненных в «германском» шпионаже. По решению Комиссии НКВД и Прокурора СССР высшая мера наказания применялась к 1610 чел. (94,8 \%), лагерное заключение - 48 чел (2,8 \%). В Омской области преследования по «немецкой» карательной акции прошли вяло, всего по приказу № 00439 прошло 43 чел., включая 15 чел. (34,8 \%) осужденных к ВМН и 26 чел. $(60 \%)$ - к ИТЛ.

По «харбинской» операции в Западной Сибири репрессиям подверглось 3143 чел., что составило 9,5 \% от общего числа прошедших по приказу НКВД № 00593 в СССР. В Новосибирской и Омской областях под преследования попали 2215 чел. и 289 чел. соответственно, в Алтайском крае - 639 чел. По-прежнему по жестокости выносимых приговоров лидировала Новосибирская область, где к расстрелу было приговорено 2119 чел. $(95,6 \%)$, а к лагерному заключению - 85 чел $(3,8 \%)$. В Алтайском крае 424 чел. (66 \%) были осуждены по первой категории, 190 чел $(29,7 \%)$ - по второй. В Омской области 152 чел. (52 \%) получили «высшку», а 132 чел. $(45,6)$ - лагерные сроки.

«Латышская» карательная акция заняла четвертое место в статистике западносибирских чекистов. По ней прошло 2283 чел., или 14 \%. Основной удар по «латышским» шпионам нанесли сотрудники УНКВД по Новосибирской области, арестовав 1874 чел. Комиссия НКВД и Прокурора СССР утвердила смертельные приговоры для 1874 чел (95 \%). В Омской области под маховик террора попало 209 чел., в том числе высшую меру наказания получили 93 чел (44 \%).На Алтае 200 чел. инкриминировали обвинение в «латышском» шпионаже, по первой категории прошли 197 чел. (98,5 \%) .

По «смешанной» операции прошло 451 чел., или 5,4 \%, при этом 373 чел. было арестовано в Новосибирской области. Расстрельные приговоры составили $90 \%$. В Алтайском крае и Омской области «смешанная» карательная акция прошла вяло, под репрессивный удар попали 58 чел. и 20 чел. соответственно. Показатель смертных приговоров также был сравнительно низким, для Алтайского края он составил 48 \%, а для Омской области - 20 \%.

По «румынской» карательной акции в Западной Сибири репрессировали 118 чел., или 1,9\%. Основные аресты прошли в Новосибирской области (93 чел.). Выносимые Комиссией НКВД и Прокурора СССР приговоры были сравнительно мягче, чем по другим «национальным» линиям, «только» в 82,7 \% случаях решения были в пользу смертной казни. В Алтайском крае 16 чел. было обвинено в «финском» шпионаже, все получили «вышку». В Омской области 9 чел. инкриминировали «шпионаж в пользу Финляндии», 4 чел. (44,5%) расстреляли, 5 чел. $(55,5)$ получили тюремный сроки.

Репрессии по «финской» линии прошли в Новосибирской и Омской областях. Всего чистке подверглось 161 чел., или 2,9%. В Омске по протоколам «двойки» прошел только один человек, получивший лагерный срок, остальные (160 чел.) были арестованы в Новосибирске. По уже сложившейся традиции 98,7 \% были расстреляны.

«Эстонская», «греческая» и «иранская» операции из трех западносибирских регионов имели место быть только в Новосибирской области. По «эстонской» карательной акции прошло 749 чел., что составило 14 \% от общего числа репрессированных в Советском Союзе. 
По «греческой» и «иранской» операциям преследованиям подверглось 42 чел. (0,4 \%) и 37 чел. (1,5 \%) соответственно. Утвержденные Комиссией НКВД и Прокурора СССР приговоры в основном были в пользу смертной казни, расстрельные приговоры составляли более $90 \%$.

Итак, из одиннадцати «национальных» карательных линий в регионах Западной Сибири имели место быть десять. «Афганская» операция здесь не проводилась. Чекисты УНКВД по Новосибирской области реализовали десять операций («польская», «немецкая», «харбинская», «латышская», «смешанная», «румынская», «финская», «эстонская», «греческая», «иранская»). В Омской области прошли 7 «национальных» линий, а именно: «польская», «немецкая», «харбинская», «латышская», «смешанная», «румынская», «финская». На Алтае сотрудникам УНКВД удалось реализовать только 6 операций, репрессии по «финской» линии здесь не проводились. Новосибирская область стала лидером не только по количеству арестованных, но и по жестокости выносимых приговоров. Здесь по «национальным» операциям прошло 13308 чел., смертельные приговоры были вынесены 12821 чел. (96 \%). В Алтайском крае в рамках «линейных» операций было арестовано 4353 чел. Репрессивные решения были мягче $(78,7 \%)$, чем в Новосибирской области. Интересно, что на Алтае операция по приказу № 00439 прошла масштабнее (2175 чел.), чем в Новосибирской области (1698 чел.). В Омской области «национальные» карательные акции прошли сравнительно вяло (1637 репрессированных). Выносимые приговоры были мягкие, доля осужденных по первой категории составляла 44,1 \%. Всего в Западной Сибири преследованиям по «национальному» признаку подверглось 19298 чел. Доля репрессированных в регионе от общего числа осужденных по «линейным» операциям в СССР составила $8 \%$.

Подводя итог, отметим, что применение статистических методов позволяет определить масштаб репрессий по «национальным» операциям как в целом по стране, так и в отдельно взятых регионах. Кроме того, использование базы данных и методов статистики позволяют увидеть особенности проведения карательных акций в республиках, краях или областях Советского Союза.

\section{Лumepamypa}

Большевистский порядок в Грузии: в 2 т. / сост.: М. Юнге, Б. Бонвеч, О. Тушурашвили. М.: АИРО-ХХІ, 2015.

Джуха И.Г. Греческая операция. История репрессий против греков в СССР. СПб.: Алетейя, 2006. $416 \mathrm{c}$.

Жанбосинова А.C., Потапова Н.А. Масштабы и региональные особенности «национальных» операций в Казахской ССР [Электронный ресурс] // Исторический курьер. 2019. № 1. URL: http://istkurier.ru/data/2019/ISTKURIER-2019-1-09.pdf (дата обращения: 02.07.2019 г.).

Жданова Г.Д. Политические репрессии на Алтае 1919-1938 гг.: историко-статистическое исследование. Барнаул: АЗБУКА, 2015. 255 с.

Звеняцкая Н.В. Социальный портрет «врага народа» в 1920-1930-е гг. (по материалам Нижнетагильского округа) // Тагильский край в панораме веков. Материалы научнопрактической конференции г. Нижний Тагил, 12-13 мая 1999 г. Екатеринбург, 1999. С. 98-104.

Из истории Всероссийской Чрезвычайной комиссии 1917-1921 гг. Сборник документов. M., 1958. C. 95-96.

Потапова Н.А. «Национальные» операции НКВД СССР в советских республиках Южного Кавказа (сентябрь 1937 - ноябрь 1938 гг.) // Вестник архивов Армении. 2018. № 126. С. 293-305.

Потапова Н.А. «Харбинская» операция в Украине (сентябрь 1937 - ноябрь 1938 гг.) // Актуальные проблемы исторических исследований: взгляд молодых ученых: сборник материалов Всероссийской молодежной научной школы-конференции. Новосибирск, 14-16 сентября 2017 г. Новосибирск, 2017. С. 209-220. 
Потапова Н.А.«Харбинская» операция НКВД СССР 1937-1938 гг. в Алтайском крае // Вестник Томского государственного университета. История. 2017. № 47. С. 75-80.

Потапова Н.А. «Харбинская» операция НКВД СССР (сентябрь 1937 - ноябрь 1938 гг.) в Красноярском крае: общее и особенное в организации и проведении репрессивной акции [Электронный ресурс] // Исторический курьер. 2019. № 1. URL: http://istkurier.ru/data/ 2019/ISTKURIER-2019-1-06.pdf (дата обращения: 02.07.2019 г.).

Разинков С.Л. Социальный портрет советских немцев-трудармейцев, мобилизованных в лагеря НКВД на территории Свердловской области в 1941-1946 гг.: опыт создания и применения электронной базы данных: автореф. дисс. ... канд. ист. наук. Екатеринбург, 2001. 24 с.

Раков A.A. Социально-экономические аспекты «раскулачивания» крестьян Южного Урала (1930-1934 гг.). М.: МАКС Пресс, 2012. 193 с.

Через трупы врага на благо народа. «Кулацкая операция» в Украинской ССР 1937-1941 гг.: в 2 т. / сост.: М. Юнге, С.А. Кокин, Р. Биннер, А.О. Довбня, Б. Бонвеч, И.Е. Смирнова, Г.А. Бордюгов; под. общ. ред. О.А. Довбни, Л.С. Макаровой. М.: РОССПЭН, 2010.

Юнге М., Биннер Р. Как Террор стал «Большим». Секретный приказ № 00447 и технология его исполнения. М.: АИРО-ХХ, 2003. 352 с.

Юнге М., Бордюгов Г., Биннер Р. Вертикаль большого террора. История операции по приказу НКВД № 00447. М., 2008.М.: Новый Хронограф; АИРО-XXI, 2008. 784c.

\section{References}

Bolshevistskiy poriadok v Gruzii [Bolshevik order in Georgia]: v 2 t. / sost.: M. Junge, B. Bonvech, O. Tushurashvili. Moscow: AIRO-XXI, 2015.

Dzhuha I.G. Grecheskaya operaciya. Istoriya repressij protiv grekov v SSSR [Greek operation. The history of repression against the Greeks in the USSR]. St. Petersburg: Aletejya, 2006. 416 p.

Zhanbosinova A.S., Potapova N.A. Masshtaby i regionalnye osobennosti «nacionalnyx» operaciy $\mathrm{v}$ Kazaxskoy SSR [Scale and regional features of "national" operations in the Kazakh SSR] [Available online:] // Istoricheskiy kurier, 2019, № 1. URL: http://istkurier.ru/ data/2019/ISTKURIER-2019-1-09.pdf

Zhdanova G.D. Politicheskie repressii na Altae 1919-1938.: istoriko-statisticheskoe issledovanie [Political repressions in Altai 1919-1938: historical and statistical research]. Barnaul: AZBUKA, 2015. 255 p.

Zvenyatskaya N.V. Social portrait of the "enemy of the people" in the 1920-1930s, in Tagil'skiy kray v panorame vekov. Materialy nauchno-prakticheskoy konferentsii g. Nizhniy Tagil [Tagil Territory in the panorama of the centuries. Materials of the scientific-practical conference in Nizhny Tagil], Yekaterinburg, 1999. P. 98-104.

Iz istorii Vserossijskoy Chrezvichaynoy komissii 1917-1921 [From the history of the AllRussian Extraordinary Commission 1917-1921]. Sbornik dokumentov. Moscow, 1958. P. 95-96.

Potapova N.A. «Harbinskaya» operaciya NKVD SSSR 1937-1938 v Altajskom krae ["Harbinian" operation of the NKVD of the USSR in 1937-1938 in Altai Krai] // Vestnik Tomskogo gosudarstvennogo universiteta. Istoriya, 2017, № 47. P. 75-80.

Potapova N.A. «Harbinskaya» operaciya v Ukraine (sentyabr 1937-noyabr 1938) ["Harbinskaya" operaciya in Ukraine (September 1937-November 1938)] // Aktualnye problemy istoricheskix issledovaniy: vzglyad molodyx uchenyx : sbornik materialov Vserossiyskoy molodezhnoy nauchnoy shkoly-konferencii. Novosibirsk, 14-16 sentyabrya 2017. Novosibirsk, 2017. P. 209-220.

Potapova N.A. "Nacionalnye" operacii NKVD SSSR v sovetskih respublikah Yuzhnogo Kavkaza (sentyabr 1937-noyabr 1938) ["National" operations of the NKVD of the USSR in the Soviet republics of the South Caucasus (September 1937-November 1938)] // Vestnik arhivov Armenii, 2018, № 126. P. 293-306.

Potapova N.A. «Harbinskaya» operaciya NKVD SSSR (sentyabr 1937 - noyabr 1938) v 
Krasnoyarskom krae: obshhee $\mathrm{i}$ osobennoe $\mathrm{v}$ organizacii $\mathrm{i}$ provedenii repressivnoj akcii ["Harbinian" operation of the NKVD of the USSR (September 1937 - November 1938) in the Krasnoyarsk Territory: general and special in organizing and conducting a repressive action] [Available online:] // Istoricheskiy kurier, 2019, № 1. Article 6. URL: http://istkurier.ru/data/2019/ISTKURIER-2019-1-06.pdf

Razinkov S.L. Sotsial'nyy portret sovetskikh nemtsev-trudarmeytsev, mobilizovannykh v lagerya NKVD na territorii Sverdlovskoy oblasti v 1941-1946 gg.: opyt sozdaniya i primeneniya elektronnoy bazy dannykh [Social portrait of Soviet German Labor Soldiers mobilized in NKVD camps in the Sverdlovsk Region in 1941-1946: experience in creating and using an electronic database], Extended abstract of PhD dissertation. Nizhniy Tagil, 2001, Russia. 24 p.

Rakov A.A. Sotsialno-ekonomicheskiye aspekty "raskulachivaniya" krest'yan Yuzhnogo Urala (1930-1934 gg.) [Socio-economic aspects of the "dispossession" of the peasants of the Southern Urals (1930-1934)]. Moscow, 2012. 193 p.

"Cherez trupy vraga na blago naroda". "Kulackaya operaciya" v Ukrainskoj SSR 1937-1941 ["Through the corpses of the enemy for the benefit of the people". "Kulak operation" in the Ukrainian SSR, 1937-1941]: v 2 t. / sost.: M. Junge, S.A. Kokin, R. Binner, O.A. Dovbnya, B. Bonvech, I.E. Smirnova, G.A. Bordyugov; pod. obshch. red. O.A. Dovbni, L.S. Makarovoy. Moscow: ROSSPEHN, 2010.

Junge M., Binner R. Kak Terror stal "Bolshim". Sekretniy prikaz № 00447 i tekhnologiya ego ispolneniya [How the Terror became "Big". Secret order № 00447 and the technology of its execution]. Moscow: AIRO-XX, 2003. 352 p.

Junge M., Bordyugov G., Binner R. Vertikal bolshogo terrora. Istoria operacii po prikazu NKVD № 00447 [Vertical of the great terror. The history of the operation by order of the NKVD No. 00447]. Moscow, 2008. Moscow: Noviy Khronograf; AIRO-XXI, 2008. 784 p.

Статья поступила в редакиию 10.08.2019 г. 